\title{
FRICTION STIR WELDING OF NEW ELECTRONIC PACKAGING MATERIALS SiCp/AI COMPOSITE WITH T-JOINT
}

\author{
Zeng Gao $^{1 *}$ - Jianguang Feng ${ }^{1}-$ Huanyu Yang ${ }^{1}-$ Jukka Pakkanen $^{2}-$ Jitai Niu $^{1}$ \\ ${ }^{1}$ School of Materials Science and Engineering, Henan Polytechnic University, Henan, Jiaozuo, 454003, P. R. China \\ ${ }^{2}$ Institute for Materials Science and Welding, Graz University of Technology, Graz, 8010, Austria
}

\begin{tabular}{l} 
ARTICLE INFO \\
\hline Article history: \\
Received: 26.04 .2017$. \\
Received in revised form: 13.12 .2017$. \\
Accepted: 02.02 .2018$. \\
\hline Keywords: \\
SiC /Al composite \\
Microstructure \\
Friction stir welding \\
Gas tightness \\
\hline
\end{tabular}

DOI: https://doi.org/10.30765/er.38.3.12

\section{Introduction}

Aluminium-based metal matrix composites (MMCs) reinforced with the ceramic particle $\mathrm{SiC}$, is an interesting structural and functional material in aerospace, motor sport, and automotive industrial fields due to its several attractive advantages over the conventional base alloy, such as high specific stiffness and strength, high thermal stability, and its superior wear resistance [1-4]. It is used as well in some other fields due to its attractive properties. For the aerospace field, material properties and structure weight are very important factors. In the aerospace field, iron-cobalt-nickel alloy Kovar and coppertungsten alloy are the most used materials in

\begin{abstract}
:
Using friction stir welding, the electronic container box and lid made from aluminium matrix composites with reinforcement of SiC particle $(15$ vol\% $\mathrm{SiC}_{\mathrm{p}} / \mathrm{Al}-\mathrm{MMCs}$ ) was welded successfully with T-joint. The temperature distribution of box during the process, mechanical property and microstructure of the joint as well as gas tightness of welded box was investigated. The experimental results indicated that the satisfactory $T$-joint can be obtained under appropriate friction stir welding parameters. During the welding process, the bottom center, which was used to place the electronic component, reached a quite lower temperature of $100^{\circ} \mathrm{C}$. That can ensure safety of components in the box. After the welding process, the microstructure in stir zone was better than in base material due to the refining and homogeneous distribution of the SiC particles. The experimental results showed that the electronic container box after friction stir welding had gas tightness. The He-leakage rate was under $10^{-8} \mathrm{~Pa} \bullet \mathrm{m}^{3} / \mathrm{s}$.
\end{abstract}

conventional application for electronic packaging manufacturing. The reason for that is that the two kinds of materials have good thermal expansion coefficient and weldability, which means that they easily get welded by conventional seam welding technology. Obviously, the disadvantages of ironcobalt-nickel alloy Kovar and copper-tungsten alloy are their high density and low heat conductivity coefficient [5-7]. In recent decades, according to the principle of lightweight design, the conventional packaging materials need to be replaced. For the potential application in the aerospace field, the new promising material $\mathrm{SiC}_{\mathrm{p}} / \mathrm{Al} \mathrm{MMCs}$ has many kinds of merits such as high heat conductivity coefficient, low density, specific high stiffness and strength.

\footnotetext{
* Corresponding author.

E-mail address: mrgaozeng@163.com
} 
However, regarding the joining of $\mathrm{SiC}_{\mathrm{p}} / \mathrm{Al}$ MMCs, it is hard to obtain defect-free welds by using conventional fusion welding methods. That deleterious reaction was observed in fusion zone between $\mathrm{SiC}$ particles. Liquid aluminium and irregular redistribution of the $\mathrm{SiC}$ particles frequently occurred, which significantly limited the joint properties of $\mathrm{SiC}_{\mathrm{p}} / \mathrm{Al}$ MMCs [8-10]. The main reason for that is high temperature during the conventional fusion welding. Besides, the flow of molten bath can cause irregular distribution of reinforcement.

Friction stir welding (FSW) is a relative new solidstate welding technology. It has been developed quite well over the past decades to join light alloy such as aluminium [11]. Until now, FSW bas been widely used for the welding of aluminium regular seam. The FSW is a suggestible candidate in joining $\mathrm{SiC}_{\mathrm{p}} / \mathrm{Al}$ MMCs since this method is a solid-state process. Hence, the brittle product such as $\mathrm{Al}_{4} \mathrm{C}_{3}$, which is produced at high temperature, is not easily generated. Moreover, due to technological characteristics, FSW can improve the distribution of $\mathrm{SiC}$ particle in stir zone significantly, making it more homogeneous. The researchers [12-14] also indicated that the friction stir action in composite can broke the reinforcement and make them more evenly distributed. This work mainly deals with welding of $\mathrm{SiC}_{\mathrm{p}} / \mathrm{Al}$ MMCs which is potentially required in aerospace electronic packaging field. The electronic container box and lid need to be welded gas tightly. Meanwhile, during welding process, the components inside of box can not be damaged because of the welding heat conduction, which requires temperature at box bottom lower than $180{ }^{\circ} \mathrm{C}$.

\section{Experimental materials and procedure}

The material used in this research is $15 \mathrm{vol} \% \mathrm{SiC}_{\mathrm{p}} / \mathrm{Al}-$ MMCs. For composites, the base material is A356, which has good formability. The chemical composition of the base material A356 is shown in Table 1.

Table 1. Chemical composition of A356 aluminum alloy (wt.\%)

\begin{tabular}{|c|c|c|c|c|}
\hline Element & $\mathrm{Si}$ & $\mathrm{Fe}$ & $\mathrm{Cu}$ & $\mathrm{Mg}$ \\
\hline Content & 7.0 & 0.12 & 0.10 & 0.45 \\
\hline Element & $\mathrm{Mn}$ & $\mathrm{Zn}$ & $\mathrm{Ti}$ & $\mathrm{Al}$ \\
\hline Content & 0.05 & 0.05 & 0.20 & Balance \\
\hline
\end{tabular}

The box and lid as shown in Figure 1, were machined from billet of composites. In previous study, the box joint type was used. However, the joint property such as gas tightness was hard to achieve. In this research, the improved $\mathrm{T}$-joint type was utilized by enlarging the lid to size of $60 \times 60 \mathrm{~mm}^{2}$. This allows the shoulder of FSW tool to be fully on top of box eliminating lamination of stirred material on lid. Container size is $27 \times 27 \times 15 \mathrm{~mm}^{3}$ and thickness of the wall is $4 \mathrm{~mm}$.

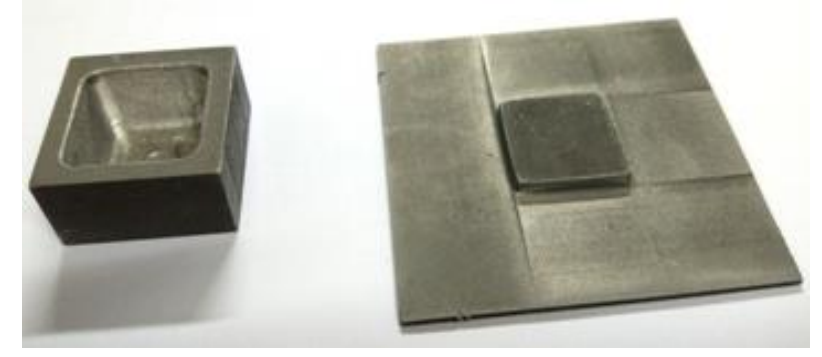

Figure 1. Shape of the box and the lid before FSW.

A MTS iSTIR BR4 friction stir welding machine was used for welding the box.

Because $\mathrm{SiC}_{\mathrm{p}} / \mathrm{Al}$-MMCs is a quite wear resistant result from $\mathrm{SiC}$ particles existing [15], the material and the shape of FSW tool need to be considered carefully. In this research, the FSW tool is made from the material of wear resistant WC-Co. To improve the FSW tool wear resistance, a cone shape tool is used in experiment. The shape and diameter of the FSW tool are given in Figure 2.

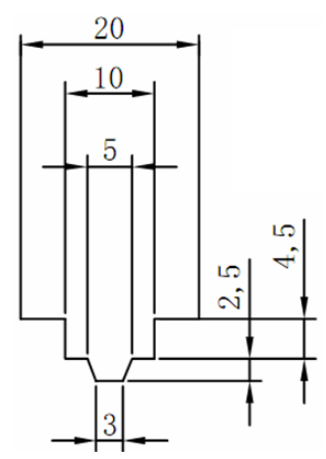

Figure 2. The FSW-tool geometry and dimension (Unit: $\mathrm{mm}$ ).

After previous optimization, the welding parameters were: spindle speed of $1500 \mathrm{RPM}$, transitional speed $120 \mathrm{~mm} / \mathrm{min}$, pressing force $2 \mathrm{kN}$, plunge depth of $2.55 \mathrm{~mm}$ and tool tilt angle of $3^{\circ}$. T-joint geometry, the FSW tool position, as well as T-joint stereomicroscope image before and after FSW are shown in Figure 3. 

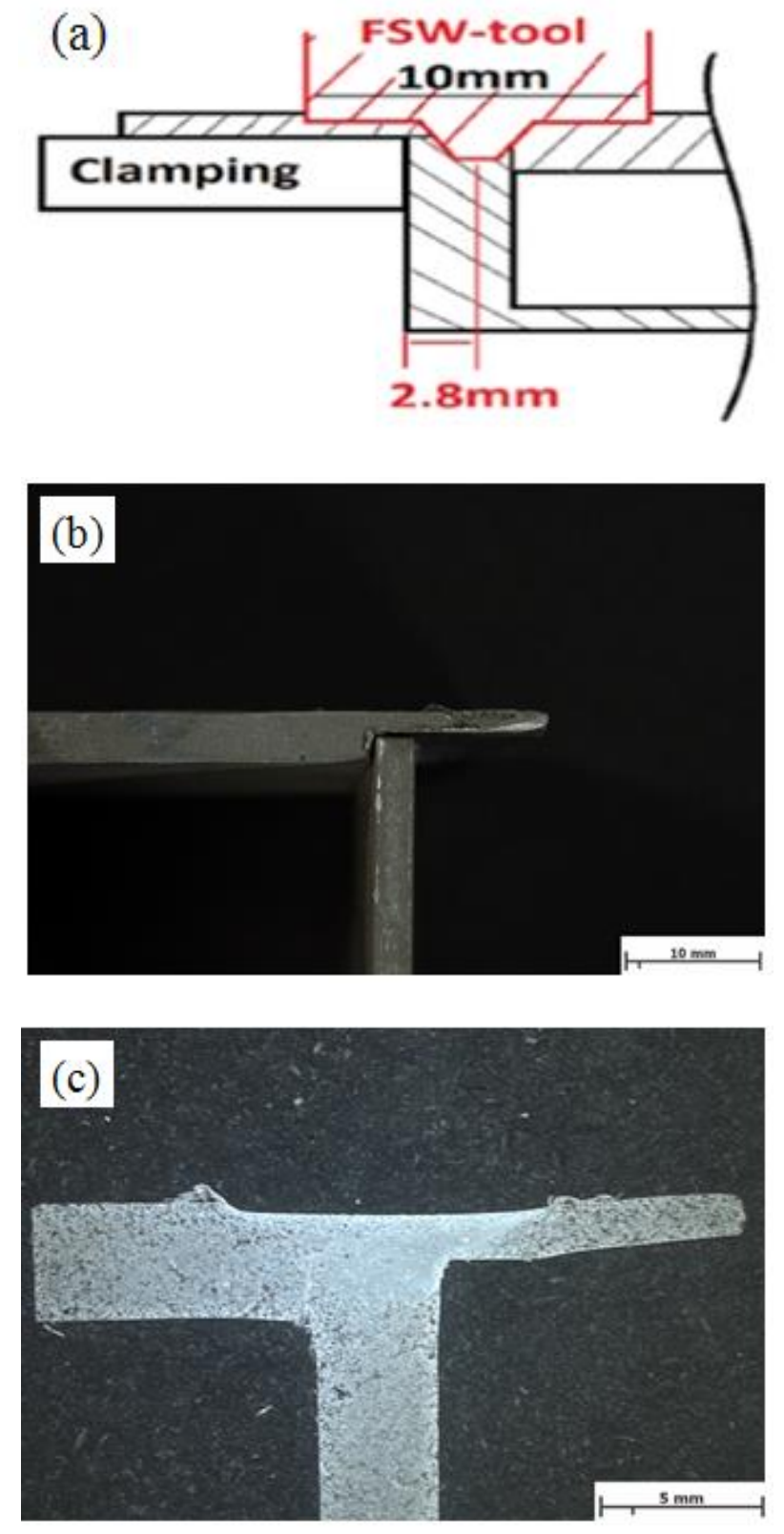

Figure 3. T-joint (a) joint geometry and the FSW-tool position, (b) image of T-joint before FSW and (c) stereomicroscope image of $T$-joint after FSW.

The temperatures were measured at specific points during FSW by using four pairs of chromium-nickel silicon thermocouples. Shearing test was performed at room temperature on the electronic universal testing machine (IIC-MST-100). During the shearing test, a constant shear rate of $0.2 \mathrm{~mm} / \mathrm{min}$ was utilized. Weld quality was checked with light microscopy. The SEM- and EDX-analysis were made with FEI, Quanta 200 microscope and EDAX-sensor. The gas tightness test was performed on helium leak mass spectrometer KYKY ZQJ-530.

\section{Results and discussion}

\subsection{Temperature distribution during the FSW process}

To protect devices in the electronic container box, temperature at the bottom center of the box needs to be limited to less than $180{ }^{\circ} \mathrm{C}$ [16]. It is determined by melting point of soldering filler metal in chips. Therefore, temperature development during the FSW is measured from four locations from the middle of the box as shown in Figure 4. Figure 5 gives the temperature measurement results.

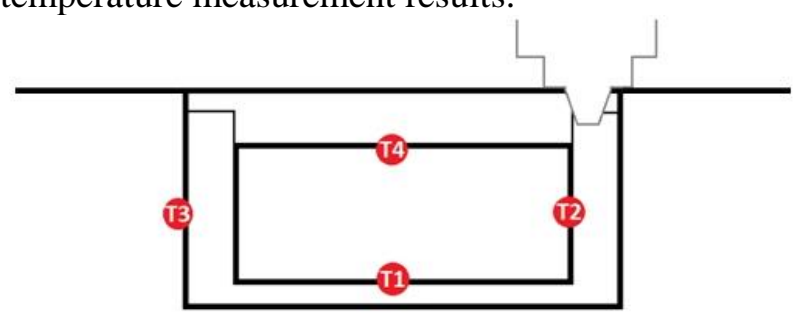

Figure 4. A cross section of the center of the box showing temperature measurements.

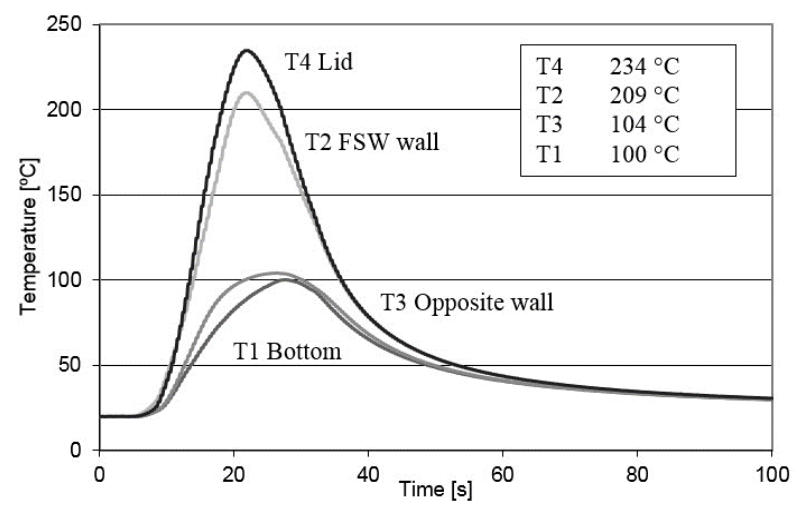

Figure 5. Temperature development during FSW and peak temperatures.

The components are placed in the bottom center of the box as shown in T1. The peak temperature during FSW at $\mathrm{T} 1$ is $100^{\circ} \mathrm{C}$, which can guarantee the safety of the components determined by melting point of $\mathrm{Sn}-\mathrm{Pb}$ solder $\left(180^{\circ} \mathrm{C}\right)$ [16]. Because welding heat mostly comes from the FSW tool shoulder during welding, it is obviously that T4 reaches the highest temperature of $234^{\circ} \mathrm{C}$. T2 is quite close to the welding center, hence it reaches the $2^{\text {nd }}$ highest temperature of $209^{\circ} \mathrm{C}$. Figure 5 also shows that peak 
temperature at $\mathrm{T} 1$ and $\mathrm{T} 3$ and later in $\mathrm{T} 4$ and $\mathrm{T} 2$. The reason for that is that the distance of $\mathrm{T} 1$ and $\mathrm{T} 3$ is larger than that of $\mathrm{T} 4$ and $\mathrm{T} 2$.

\subsection{Mechanical property of the joint}

The shear test was done in $100 \mathrm{kN}$ computer controlled bench. Computer was recording the force and elongation of the specimen. The sampling position for the shearing test on the box was shown in Figure 6.

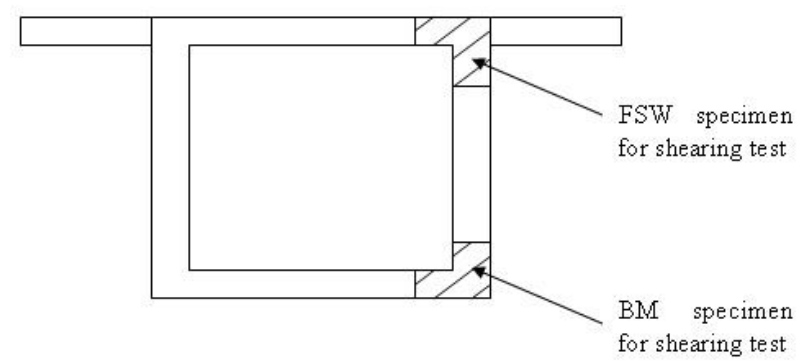

Figure 6. Sampling positions for the shearing test on the electronic container box.

For base material (BM) and FSW specimen, Figure 7 is manufactured and tested. Five specimens of BM and FSW sections were used for the shearing test. Stir zone is shown in section line region. The stir zone is in the middle and the lack of wall fusion is starting the shear.

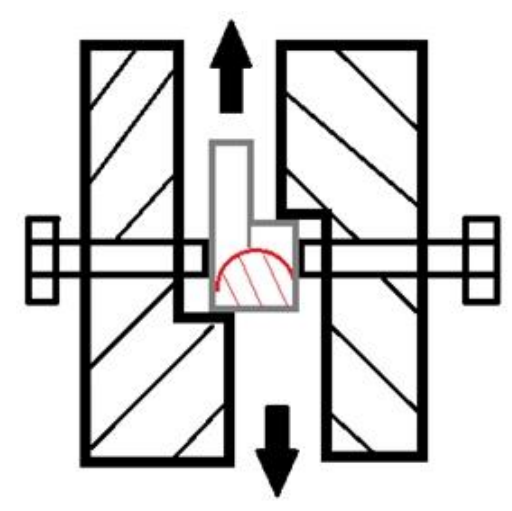

Figure 7. The shear test of FSW specimen.

To protect test fixture, the shear displacement was limited to less than $3 \mathrm{~mm}$. With $\mathrm{BM}$ and FSW specimens, the shear test maximum force was exceeded. The FSW specimen wall-lid interface had opened but the material hadn't broken thoroughly. Regarding the BM specimen, the second shear test broke specimen with the help of plastic deformation from the first test. Joining of BM and FSW is too good to be tested with a way shown in Figure 7. With the same FSW process parameters, tensile specimen was manufactured then. In the tensile test, it can be found that breakage occurred in the base material as given in Figure 8, which means that mechanical property in the FSW joint is better than that in the base material. That has significant relationship with microstructure and particle distribution in joint of $\mathrm{SiC}_{\mathrm{p}} / \mathrm{Al} \mathrm{MMCs}$, which will be analyzed in part of the microstructure.

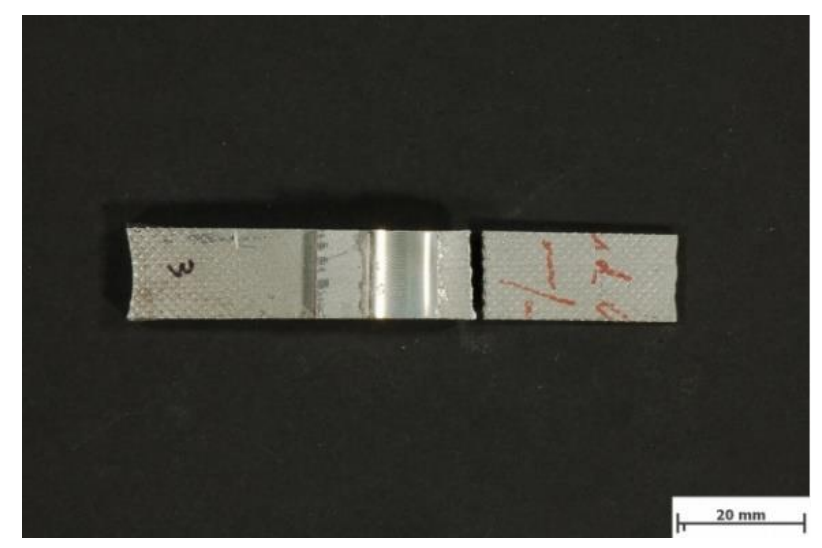

Figure 8. The tensile test result of $\mathrm{SiC}_{\mathrm{p}} / \mathrm{Al} \mathrm{MMCs}$ joint.

\subsection{Microstructure of the FSW joint}

Figure 9 shows the box after FSW from bottom and top looking as well as the clamping device used in the experiment. After the FSW, four keyholes will be left in the box lid. However, excessive lid with keyhole will be cut away before application.

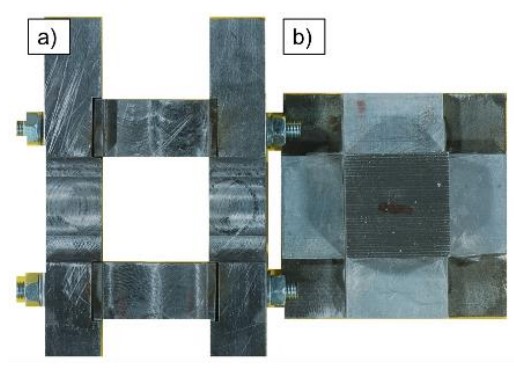

c)

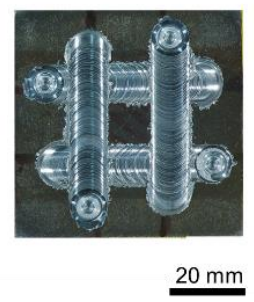

Figure 9. FSW box: (a) clamping device, (b) bottom look of FSW box and (c) top look of FSW box.

Figure 10 shows microstructure distribution of ascasted 15 vol\% $\mathrm{SiC}_{\mathrm{p}} / \mathrm{Al}-\mathrm{MMCs}$ used in this research. The microstructure for as-casted composite consists 
of $\alpha$-aluminium, eutectic $\mathrm{Si}$ and $\mathrm{SiC}$ particles. The distribution of the $\mathrm{SiC}$ particles in base aluminium is not very uniformed. Most of the $\mathrm{SiC}$ particles distribute on grain boundary of base metal. The reason for that is that during casting manufacturing, the $\mathrm{SiC}$ particles are pushed to the grain boundary region driving by solidification force.

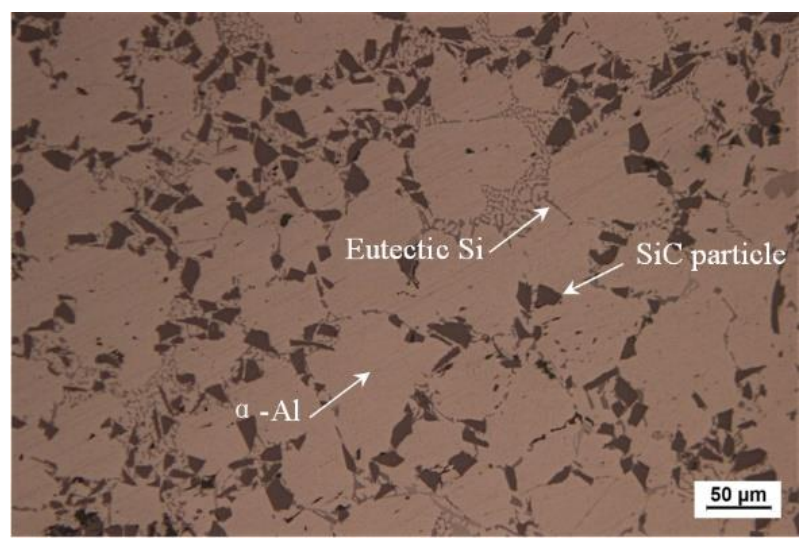

Figure 10. Microstructure of $15 \mathrm{vol} \% \mathrm{SiC}_{p} / \mathrm{Al}$-MMCs.

T-joint of 15 vol\% $\mathrm{SiC}_{\mathrm{p}} / \mathrm{Al}$-MMCs was successfully welded by the FSW. As shown in Figure 11, microstructure of the FSW T-joint is separated into four regions: (a) stir zone (SZ); (b) thermomechanical affected zone (TMAZ); (c) heat affected zone (HAZ); and (d) parent material.

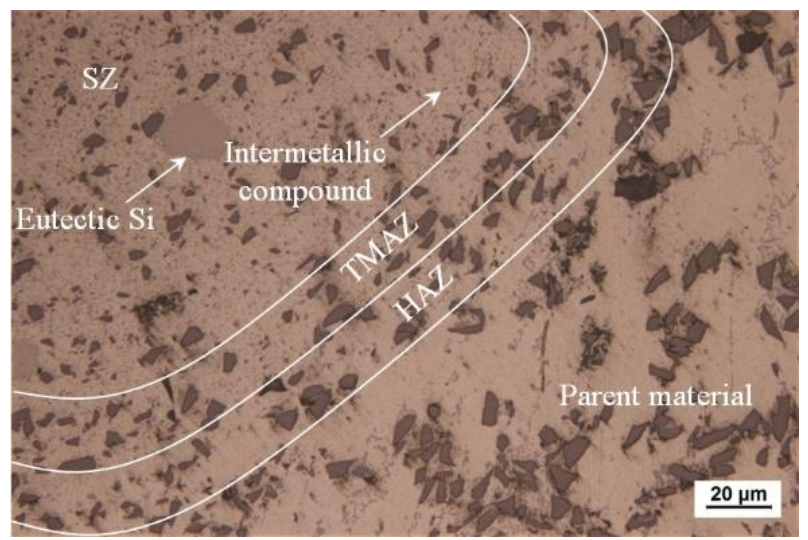

Figure 11. Microstructure of FSW joint of 15 vol\% $\mathrm{SiC}_{\mathrm{p}} / \mathrm{Al}$-MMCs with four zones.

Because of severe deformation and stirring during the FSW process, the SiC particles distribution in SZ becomes more even, meaning the re-arrangement of the $\mathrm{SiC}$ particles. Moreover, the size of the $\mathrm{SiC}$ particles in SZ is smaller than that in parent metal due to particle breakage during friction and stirring. It can be found that the FSW joint is free from defects such as void and groove in SZ. Meanwhile, blocky eutectic $\mathrm{Si}$ and precipitation product such as intermetallic phase can be observed in this area as well. The homogeneous distribution and smaller size of particle in SZ will promote joint mechanical property in this area. As is shown in tensile test, breakage occurred in base material rather than in the joint. The TMAZ, which is adjacent to SZ, has been plastically deformed and thermally affected. In TMAZ, clustered $\mathrm{SiC}$ particles are redistributed slightly as well. The particles distribution follows orientation of material flow in TMAZ. The HAZ between TMAZ and parent material exhibits a similar microstructure compared to base composite.

Figure 12 shows the EDX analysis points defined on SEM microstructure of composite in stir zone. Figure 12 (a) describe results of the EDX analysis which are taken from indicated points represented in fine $\mathrm{SiC}$ particles, Figure 12 (b) represented to matrix alloy, respectively. Figure 12 (a) shows that $\mathrm{Si}, \mathrm{C}$ and $\mathrm{Al}$ peaks are mainly present.

Figure 13 describes SEM image in stir zone and EDX distribution maps of $\mathrm{Al}$ and $\mathrm{Si}$ in the same photograph. The EDX results highlighted element distribution of $\mathrm{Al}$ and $\mathrm{Si}$. $\mathrm{Al}$ and $\mathrm{Si}$ are represented by red and green area, respectively. $\mathrm{Al}, \mathrm{Si}$ and $\mathrm{C}$ distributions investigated by the EDX analysis consisted with SEM image, as shown in Figure 13 (a). The presence of coarse and fine $\mathrm{SiC}$ particles in $\mathrm{SZ}$ is also revealed by the EDX analysis of $\mathrm{Al}, \mathrm{Si}$ and $\mathrm{C}$.

\subsection{Gas tightness of the FSW joint}

Gas tightness was measured with helium leak mass spectrometer KYKY ZQJ-530. Excessive box lid was cut away before testing. Welding defects such as gap, groove, and void in joint might trap He-gas and affect gas tightness results. In the experiment, specimen was put into gas chamber that was flooded with $0.4 \mathrm{MPa}$ of He-gas and kept there for 30 minutes. From the chamber, an individual sample was rinsed with fresh air to remove helium gas on the surface and put into vacuum chamber. The gas analysator was at pressure of $10^{\wedge}-10 \mathrm{~Pa}$. The chamber holding the sample was made into $10^{\wedge}-10 \mathrm{~Pa}$ pressure and connected to analysator. After connection, the vacuum of total system without pump was read. The vacuum drop of 4 decades indicated that the sample was not gas tight.

Testing of an empty box or a half box as shown in Figure 14 was made by putting it on top of soft vinyl plate from where was a hole to vacuum hose. 

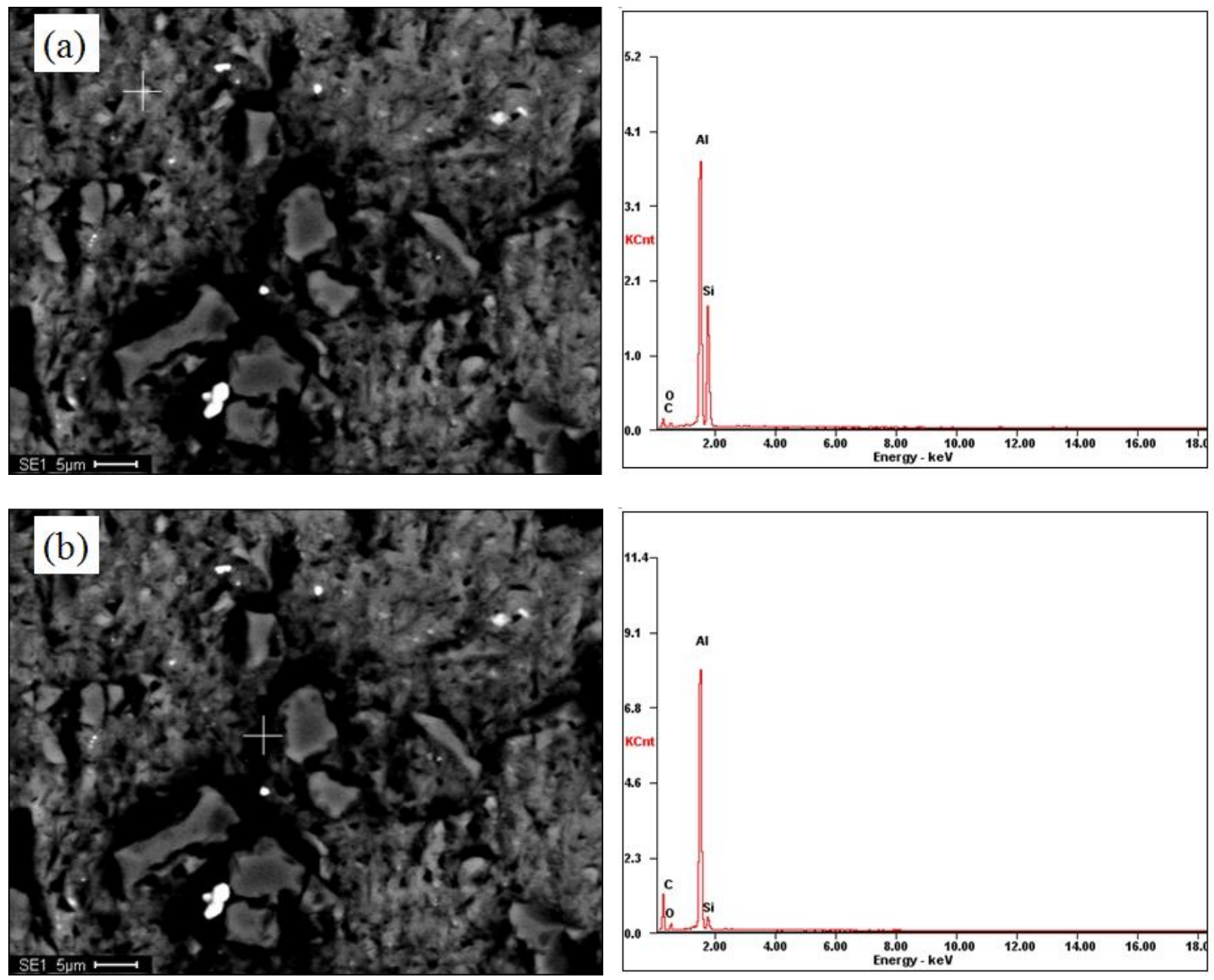

Figure 12. The SEM microstructure of the composite in stir zone and the EDX analysis results take from: (a) fine SiC particle and (b) matrix alloy
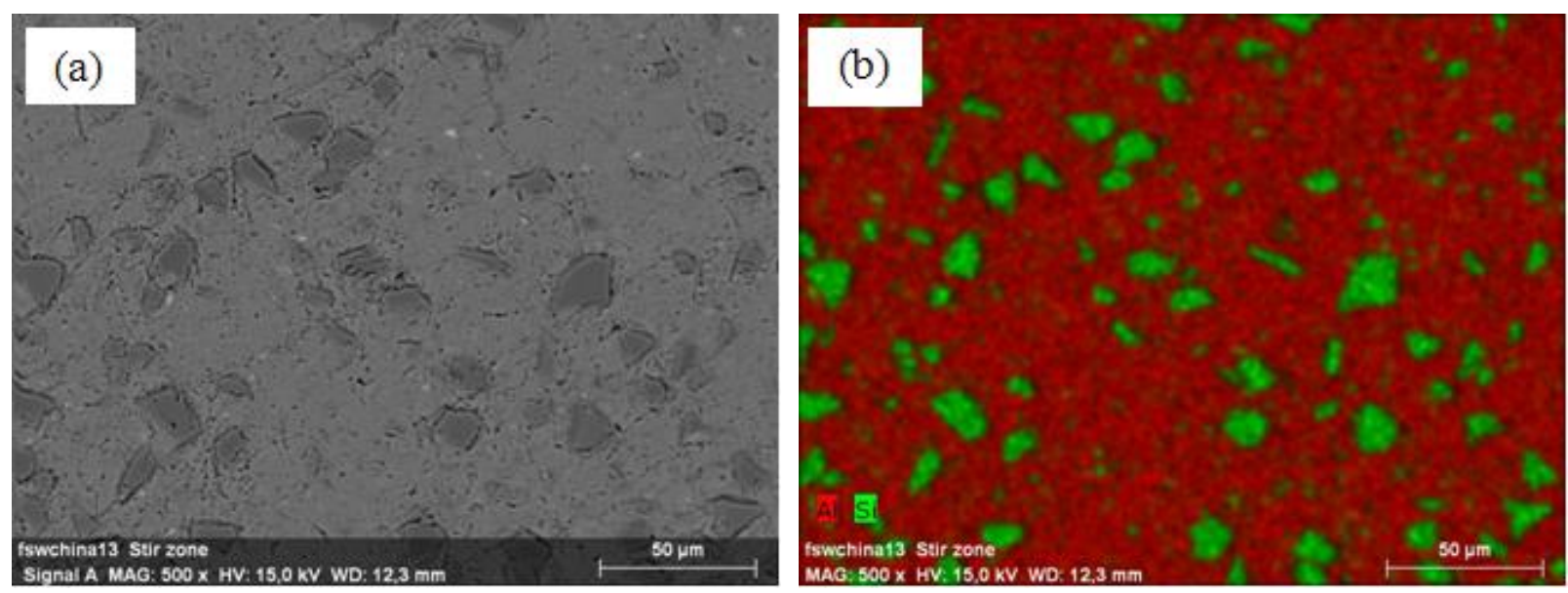

Figure 13. The SEM image of stir zone and EDX distribution maps of Al and Si in the same image:

(a) The SEM microstructure of composite in stir zone, and (b) The EDX distribution map of Al (red area) and Si (green area). 
Vacuum of $10^{-10} \mathrm{~Pa}$ was sucked from under to inside of the box. Helium gas was then sprayed on top of specimen and helium leaking through joint defect and base material was measured.

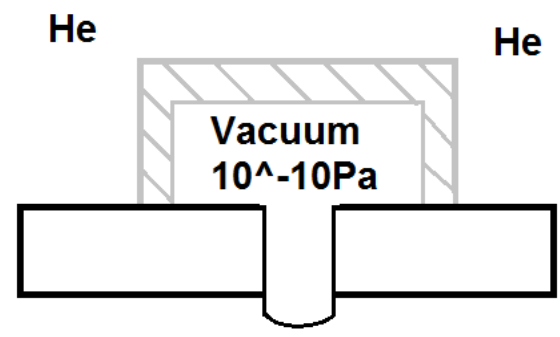

Figure 14. Gas tightness test for half box.

In the experiments, five boxes and ten half boxes were measured to examine the joint gas tightness. The mass spectrometer analysis indicated that $\mathrm{He}$ leakage rates of 15 specimens were all between $10^{-8} \mathrm{~Pa} \cdot \mathrm{m}^{3} / \mathrm{s}$ and $10^{-9} \mathrm{~Pa} \cdot \mathrm{m}^{3} / \mathrm{s}$, which meant that the specimens were all gas tight. Therefore, the FSW technology and process parameter in this work was appropriate for the welding of electronic packaging container made from $15 \mathrm{vol} \%, \mathrm{SiC}_{\mathrm{p}} / \mathrm{Al}-\mathrm{MMCs}$.

\section{Summary and conclusion}

In this work, electronic container box made from 15 vol\% $\mathrm{SiC}_{\mathrm{p}} / \mathrm{Al}$-MMCs was welded by the stir welding successfully. The satisfactory joint was obtained as well. Temperature development in the box during the FSW process, mechanical property and microstructure of the joint, as well as gas tightness of the FSW box were studied.

The following conclusions can be drawn from this work:

(1) The friction stir welding is a promising candidate for joining of $15 \mathrm{vol} \%, \mathrm{SiC}_{\mathrm{p}} / \mathrm{Al}-\mathrm{MMCs}$. For electronic packaging container, satisfied joint can be produced by the FSW technique with a TJoint. The appropriate FSW parameters for the container box in this work are following: spindle speed of 1500 RPM, transitional speed 120 $\mathrm{mm} / \mathrm{min}$, pressing force $2 \mathrm{kN}$, plunge depth of $2.55 \mathrm{~mm}$ and tool tilt angle of $3^{\circ}$.

(2) The maximum temperature reached at the lid center is $209^{\circ} \mathrm{C}$, and that in the center of friction stir welded wall is $234^{\circ} \mathrm{C}$. The bottom center, which is used to place electronic components, reaches a temperature of $100^{\circ} \mathrm{C}$ during the whole FSW process. The process parameters can guarantee safety of the components determined by melting point of $\mathrm{Sn}-\mathrm{Pb}$ solder $\left(180^{\circ} \mathrm{C}\right)$.

(3) The SiC particles in stir zone will be broken and refined due to the friction stir welding. Some $\mathrm{SiC}$ particles flake to smaller pieces. Meanwhile, the distribution of the $\mathrm{SiC}$ particles in the stir zone is more homogeneous due to high deformation and stirring. The microstructure of $15 \mathrm{vol} \% \mathrm{SiC}_{\mathrm{p}} / \mathrm{Al}-$ MMCs in the stir zone is better than that in parent material.

(4) The electronic container boxes manufactured by the FSW are gas tight. Lower He-leakage rate (between $10^{-8} \mathrm{~Pa}^{3} \mathrm{~m}^{3} / \mathrm{s}$ and $10^{-9} \mathrm{~Pa} \cdot \mathrm{m}^{3} / \mathrm{s}$ ) can be reached. The mechanical property of the FSW joint is better than that of parent material due to refining and homogeneous distribution of the $\mathrm{SiC}$ particles in the stir zone.

\section{Acknowledgments}

The authors thank for financial support of Henan Postdoctoral Foundation and Doctoral Foundation of Henan Polytechnic University (No. B2014-006).

\section{References}

[1] Wang, W., Li, Q., Ma, R., Cao, X., Cui, Y., Fan, Y., Yang, T., Liu, B.: Superior bending and impact properties of SiC matrix composites infiltrated with an aluminium alloy, Ceramics International, 43(2017), 5, 4551-4556.

[2] Hamdy, A.S., Alfosail, F., Gasem, Z.: Ecofriendly, cost-effective silica-based protective coating for an A6092SiC17.5p aluminum metal matrix composite, Electrochimica Acta, 89(2013), 749-755.

[3] Gao, Z., Niu, J., Yang, S., Wang, X., Cheng, D.: Soldering of aluminum matrix composites SiCp/A356 and Kovar alloy, Engineering Review, 33(2013), 2, 123-128.

[4] Koli, D.K., Agnihotri, G., Purohit, R.: Advanced aluminium matrix composites: the critical need of automotive and aerospace engineering fields, Materials Today Proceedings, 2(2015), 30323041.

[5] Yoon, J.W., Jung, S.B.: Investigation of interfacial reaction between $\mathrm{A} u-S n$ solder and Kovar for hermetic sealing application, Microelectronic Engineering, 84(2007), 11, 2634-2639.

[6] Gao, Z., Chen, Z., Xu, D., Wang, P., Niu, J., Wang, X.: Vacuum brazing between 


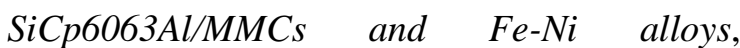
Engineering Review, 36(2016), 3, 249-254.

[7] Tan, C.W., Chan, Y.C., Leung, B.N.W., Tsun, J., So, A.C.K.: Characterization of Kovar-toKovar laser welded joints and its mechanical strength, Optics \& Lasers in Engineering, 43(2005), 2, 151-162.

[8] Shen, P., Wang, Y., Ren, L., Li, S., Liu, Y., Jiang, Q.z: Influence of SiC surface polarity on the wettability and reactivity in an $\mathrm{Al} / \mathrm{SiC}$ system, Applied Surface Science, 355(2015), 930-938.

[9] Storjohann, D., Barabash, O.M., David, S.A., Sklad, P.S., Bloom, E.E., Babu, S.S.: Fusion and friction stir welding of aluminum-metal-matrix composites, Metallurgical and Materials Transactions A, 36(2005), 11, 3237-3247.

[10] Urena, A., Escalera, M.D., Gil, L.: Influence of interface reactions on fracture mechanisms in TIG arc-welded aluminium matrix composites, Composites Science \& Technology, 60(2000), 4, 613-622.

[11] Staron, P., Kocak, M., Williams, S.: Residual stresses in friction stir welded Al sheets, Applied Physics A, 350(2002), 1, 1161-1162.
[12] Salih, O.S., Ou, H., Sun, W., Mccartney, D.G.: A review of friction stir welding of aluminium matrix composites, Materials \& Design, 86(2015), 61-71.

[13] Fernandez, G.J., Murr, L.E.: Characterization of tool wear and weld optimization in the frictionstir welding of cast aluminum 359+20\% SiC metal-matrix composite, Materials Characterization, 52(2004), 1, 65-75.

[14] Amirizad, M., Kokabi, A.H., Gharacheh, M.A., Sarrafi, R., Shalchi, B., Azizieh, M.: Evaluation of microstructure and mechanical properties in friction stir welded $A 356+15 \% \quad \mathrm{SiC}_{p}$ cast composite, Materials Letters, 60(2006), 4, 565568.

[15] Bist, A., Saini, J.S., Sharma, B.: A review of tool wear prediction during friction stir welding of aluminium matrix composite, Transactions of Nonferrous Metals Society of China, 26(2016), 8, 2003-2018.

[16] Wu, G., Zhang, Q., Chen, G., Jiang, L., Xiu, Z.: Properties of high reinforcement-content aluminum matrix composite for electronic packages, Journal of Materials Science: Materials in Electronics, 14(2003), 1, 9-12. 